\title{
Erosion Control Treatment Using Geocell and Wheat Straw for Slope Protection
}

\author{
Xiaoruan Song $\mathbb{D},{ }^{1}$ Miansong Huang $(\mathbb{D}),{ }^{2}$ Shiqin He $\mathbb{D}^{1},{ }^{1}$ Gaofeng Song $\mathbb{D},{ }^{1}$ Ruozhu Shen $\left(\mathbb{D},{ }^{3}\right.$ \\ Pengzhi Huang $\mathbb{D}^{1}{ }^{1}$ and Guanfang Zhang $\mathbb{D}^{1}$
}

${ }^{1}$ School of Civil Engineering, North China University of Technology, Beijing 100144, China

${ }^{2}$ Ningxia Capital Sponge City Construction \& Development CO., Ltd., Guyuan 756000, Ningxia, China

${ }^{3}$ Beijing Capital Co. Ltd., Beijing 100044, China

Correspondence should be addressed to Miansong Huang; hms@capitalwater.cn and Gaofeng Song; song.gaofeng@ncut.edu.cn

Received 10 February 2021; Accepted 24 March 2021; Published 12 April 2021

Academic Editor: Qing-Xin Ren

Copyright ( 92021 Xiaoruan Song et al. This is an open access article distributed under the Creative Commons Attribution License, which permits unrestricted use, distribution, and reproduction in any medium, provided the original work is properly cited.

Slope failure triggered by soil erosion under rainfall remains one of the most difficult problems in geotechnical engineering. Slope protection with planting vegetation can be used to reinforce the soil and stabilize the slope, but the early collapse of the planting soil before the complete growth of plants becomes a major issue for this method. This paper has proposed a composite soil treatment and slope protection method using the geocell structures and the wheat straw reinforcement. The geocell structures improve the stability of the planting soil and provide a stable and fixed environment for the vegetation, while the wheat straw reinforces the soil and also increases the fertility. The authors have performed a total of 9 experiments in this work that are classified into three groups, i.e., the unsupported slopes, the geocell reinforced, and the geocell and wheat straw composite reinforced with a consideration of three different rainfall intensities. The progressive slope failure development during the rainfall was assessed, as well as the soil erosion, the slope displacement, and the water content. The results show that the slope failure increases as the rainfall continues, and the soil degradation increases with the intensity of rainfall. The soil treatment using geocell improves the slope stability, but the geocell and wheat straw composite reinforcement has the best erosion control and slope protection.

\section{Introduction}

Shallow slope failure refers to a superficial removal of vegetation cover and topsoil, which is a common problem typically observed in areas of hilly or mountainous terrain, engineered road, and embankments. The shallow slope failure can be addressed as the shallow landslide and shallow soil erosion. Shallow landslide occurs when the forces acting on the downslope exceed the mechanical resistance of the slope, while erosion may occur under rainfall when the rain water dislodges soil particles and carries them off a lope, forming rills and gullies that may eventually trigger landslides. Shallow slope failure is a worldwide serious geologic hazard and causes severe adverse impacts on both natural environment and human properties. Slope protection with planting vegetation is commonly used for improving the slope stability from hydrological and mechanical aspects, such as removing water from the soil, increasing the cohesion of the soil, and anchoring the weak soil to the stable soil and the surface-mat effect. The geocell structure combining with the planting vegetation for soil reinforcement and erosion control is a new type of slope protection and ecological restoration. The cellular shade geocell structures can fix the planting soil (local soil deployed to the bare soil of the original slope for seeding) onto the slope, which offers a stable and suitable fostering environment for the plant growth. This erosion control method provides a protective layer for the slope, so that the negative impact of the rainfall does not reach the slope surface directly, while the roots of the fully grown plants on the protective layer reach down beyond the protective layer and further stabilize the slope. Other advantages such as a short construction period and 
low maintenance charges can also be identified for this environmentally-friendly and ecologically-friendly method of slope protection [1-4]. The disadvantage, on the other hand, is that the soil for planting vegetation on the surface of the slope may collapse before the plants start to stabilize the slope at fully grown. The collapse of the planting soil occurs especially at the early stage of construction under a heavy rainfall. The failure of the soil reinforcement re-exposes the original slope to the rainfall, which increases the risk of landslide. Hence, the early stability of the geocell-reinforced soil with planting vegetation is the major concern for the engineers.

This paper has proposed a composite soil treatment method for slope protection using the geocell structures and the wheat straw. The geocells are buried into the planting soil, and the wheat straw is mixed with the soil for reinforcement at the shallow depth. The advantages for the composite treatment are listed as follows: (1) the strawreinforced soil presents larger cohesion and internal angles than the original untreated soil; the shear strength is therefore enhanced with better performance against the rainfall erosion; (2) since the shallow soil at the top layer of the slope is reinforced with the wheat straw, the permeability of the soil is reduced with less pores existed, which slows down the penetration of rain water and improves the slope stability; (3) by mixing the straw with the soil, the weight of straw gradually decreases as microorganisms grow and break down the straw. The decomposition of the wheat straw increases the fertility by providing nitrogen or other nutrients in soil and fosters the growth of vegetation planting on the slope. The root system of the plants in return reinforces the geocell-reinforced soil, which further improves the slope stability.

\section{Pertinent Literature Review}

A number of studies on the geocell-reinforced slopes have been performed to study the design, construction, and mechanism of geocell reinforcement. Yang and Wang proposed a construction technique for reinforcement of slopes with small inclination using geocells, which was applied to the loess slope in northwest China [5]. Yan et al. performed experiments on the reinforcement of different geocells to the loess slopes and compared the reinforcement mechanism and erosion control of the geocell structures [6]. Rosen recognized the positive impacts of the geocells on stabilizing the slopes [7]. Sato and Kojma utilized the geocells and soil nailing in the embankment reinforcement to protect the slopes from the frequent heavy rainfall and earthquake [8]. Arvin et al. investigated the 3D slope stability reinforced by the geocells using strength reduction method, with a consideration of the interaction of geocells to the filling soils [9]. Wesseloo et al. performed the uniaxial compressive experiment to the geocells with different sizes and revealed the positive relationship between the strength of geocell-soil structure and the geocell size [10]. Latha et al. compared the influence of geocell tensile stiffness, size, and filling materials to the road embankment reinforcement in the laboratory and concluded that the reinforced geocells improve the loading bearing capacity of the embankment with reduced deformation [11].

The reinforcement of soil using the wheat straw has long been recognized in China. The application of wheat straw reinforced soil is widely found in construction of soil walls, soil houses, and embankment [12]. This is because the tensile strength of the straw and its coupling with the soil improves the shear strength. Therefore, some researchers have performed studies on the properties of the wheat straw reinforced soil. Löbmann et al. believed that the herbaceous vegetation is faster than the lignose in changing and improving the soil environment [13]. Bouhicha et al. verified from laboratory tests that the wheat straw reinforcement reduces the shrinkage of the soil and that the stabilization of the soil is quicker with better strength [14]. Ashour et al. found that the straw treatment improves the strength and ductility of the reinforced soil [15]. Zhang et al. proposed a rice straw reinforcement method for erosion control and slope protection [16]. Su et al. discussed the influence of the interaction of roots with the soil and its impact to the rootsoil mechanical properties [17]. Dias et al. considered the root penetrated soil as a composite material. An equivalent cohesion was proposed to the Mohr-Column equation [18]. Hao et al. performed the triaxial shear experiment on the soil at different reinforcement lengths and ratios [19]. The microstructures of the reinforced soil and the original soil under loading were scanned by CT. The results show that the wheat straw reinforcement improves the shear strength and the resistance to deformation.

Researchers have been mostly focused on the geocellreinforced slope or the slope protection with planting vegetation independently. However, the erosion control using the composite geocell and vegetation reinforcement has not been seen in previous works. The early stability of the planting vegetation is also widely ignored. This paper attempts to study stability of the geocell and wheat straw reinforced slope under different rainfall conditions. The paper has four main goals: (1) develop a number of physical models with no reinforcement, geocell reinforcement, and the geocell and wheat straw composite reinforcement; (2) simulate the artificial rainfall at different rainfall intensities to the physical slopes; (3) obtain progressive development of slope failures at different reinforcement and rainfall intensities; and (4) assess the impacts of the reinforcement and rainfall intensity by analysing the soil erosion, slope displacement, and water content.

\section{Model Development}

3.1. Experimental Design. In this work, the authors have developed 9 modelling tests in 3 groups with a consideration of the geocell reinforcement to the slope soil, the wheat straw reinforcement, and the rainfall intensity. The slope ratio (rise/run) is determined as $1: 1.5$ for all the models, which is commonly seen in the studied site, Yinchuan, Ningxia province. In Group A, the slopes are unsupported and constructed using the common planting soil from Yinchuan city. The slopes in Group B are reinforced with the geocell structure with a dimension of $370 \times 370 \times 150 \mathrm{~mm}$ 
(length $\times$ width $\times$ height). In Group $\mathrm{C}$, however, the slope soil is reinforced with the geocell and wheat straw. Table 1 lists the total of 9 models developed in this paper.

The rainfall intensity is calculated from equation (1) that has been developed for the Yinchuan city [20,21]:

$$
q=\frac{242 \cdot(1+0.83 \lg P)}{t^{0.477}},
$$

where $q$ is the rainstorm intensity in $\mathrm{L} /(\mathrm{s} \cdot \mathrm{ha}$ ), ( $L$ for litre, $s$ for second, and ha for hectare); $P$ is the time of duration for the occurrence of a rainstorm in a; and $t$ is the duration of the rainfall in min. Based on the rainfall statistics on the studied site, the time of duration for the occurrence of a rainstorm is selected as $10 \mathrm{a}$, and the time of duration of a rainfall is 5 minutes. From equation (1), the rainfall intensity on the studied site in Yinchuan is calculated as $75 \mathrm{~mm} / \mathrm{h}$.

The rainfall intensity in the experiment is based on the calculated average value from the studied site. For comparison, another two rainfall intensities of $50 \mathrm{~mm} / \mathrm{h}$ and $100 \mathrm{~mm} / \mathrm{h}$ are selected to study the influence of rainfall on the stability of slopes (Table 1). Since the soil erosion of slopes in the field is a result of rainfalls for years, the duration of rainfall in the experiment is determined as 30 minutes.

\subsection{Model Preparation}

3.2.1. Materials and Modelling Rig. The physical material in this study for constructing the slopes is the planting soil extracted from the studied site (Figure 1(a)). The water content and the maximum dry density is $12 \%$ and $1.7 \mathrm{~g} / \mathrm{cm}^{3}$, respectively. The geocells are selected to reinforce and stabilize the slope soil in Groups B and C. The geocell is $370 \mathrm{~mm}$ in length and width and $150 \mathrm{~mm}$ in height, with a thickness of $1.2 \mathrm{~mm}$ (Figure $1(\mathrm{~b})$ ). The top $10 \mathrm{~cm}$ layer of the constructed slopes in Group C is also reinforced with the wheat straw. The wheat straw is selected from the current year and shows good resilience. The straw is $4-5 \mathrm{~mm}$ in diameter and cut to a length of $3-5 \mathrm{~cm}$ (Figure 1(c)). The wet planting soil and the wheat straw is fully mixed before construction of the model (Figure 1(d)), and the reinforcement ratio of the slope soil after the straw treatment is $0.5 \%$ in terms of weight.

The physical models are simulated by filling soil to a modelling rig with adjustable angles [22, 23]. Figure 2 shows the modelling rig used in this study for simulating the slope soil treatment using the geocells and wheat straw. The modelling rig is $3000 \mathrm{~mm}$ in length, 1200 in width, and $500 \mathrm{~mm}$ in height (Figure 2(a)). A plate is placed in the centre of the rig, so that two slope models can be developed in the rig at the same time for direct comparison, each with a width of $30 \mathrm{~mm}$. Two runoff ports are forged at the front side of the modelling box to collect the rain water running down from the slope surface. Four smaller ports are also found at lower section of the front rig for collecting the penetration of water from the surface. The angle of the modelling rig can be easily adjusted by lifting the rear side of the rig, so that different slope ratios can be modelled. The slope ratio for this study is $1: 1.5$. The forged rig is shown in Figure 2(b).
3.2.2. Model Construction Procedure. The model construction procedures consist of the setup of the drainage system, the construction of physical slopes, and the adjustment of slope angle to the designed ratio.

(1) Drainage system at the bottom: before pouring the slope soil into the modelling rig, the drain board is placed at the bottom of the box, followed by a thin layer of geotextile that is permeable. The drain board and geotextile are so placed that the penetration of water can be restored.

(2) Construction of slope: the slope is constructed on the base soil, which refers to the bare soil of the original slope before the planting of the vegetation. Therefore, the base soil is first placed evenly on the drainage system. The base soil is fully compacted so that its thickness is less than $10 \mathrm{~cm}$ (Figure 3(a)). The total thickness of the above slope soil is $40 \mathrm{~cm}$ after compaction. For the unsupported slope in Group A, the base soil and the slope soil are placed in the modelling rig layer by layer and compacted to the designed height. Extra soil is swept from the top to make sure that the slope surface is flat and has the same height with the runoff port. For the geocellsupported slope in Group B, the geocell is placed on the base soil and is fully extended and fixed using the U-shaped nails (Figure 3(b)). The geocell rooms are then filled with the slope soil (Figure 3(c)) and compacted to the same height to models in Group A. To ensure this, same amount of soil is used for all the models in three groups. The composite supported slopes in Group C, however, are extra reinforced with the wheat straw at the top $10 \mathrm{~cm}$ layer using the mixed soil (Figure 1(d)). The construction of the slopes at both sides of the rig is conducted at the same time.

(3) Slope ratio adjustment: the finished model is given in Figure 3(d). After the placement of all the measuring devices, the rear side of the modelling rig is lifted to the designed slope ratio of $1: 1.5$, which is shown in Figure 3(e).

3.2.3. Rainfall Simulation System. After the construction of the slopes, the artificial rainfall simulation system is installed above the models. The system is designed based on the previous studies $[24,25]$ and is shown in Figure 4 . The system consists of the rotermeter, sprayers, and water flow switch, which are connected by a number of PPR pipes, two connectors, and three connectors. The total 5 sprayers are uniformly distributed above the centre line of the modelling rig, so that the entire area of the two slopes can be evenly covered (Figure 4). The artificial rainfall system enables a simulation of rainfall intensity from $10 \mathrm{~mm} / \mathrm{h}$ to $150 \mathrm{~mm} / \mathrm{h}$.

3.2.4. Measuring System. This paper considers the development of slope failures during the rainfall, the amount of soil erosion, the slope displacement, and the variation of water content for the slopes. The slope failures are captured 
TABLE 1: Soil reinforcement and rainfall intensity for different models.

\begin{tabular}{|c|c|c|c|}
\hline Model & Slope & Soil reinforcement & Rainfall intensity $(\mathrm{mm} / \mathrm{h})$ \\
\hline A1 & \multirow{3}{*}{ Unsupported slope } & \multirow{3}{*}{ Planting soil } & 50 \\
\hline $\mathrm{A} 2$ & & & 75 \\
\hline A3 & & & 100 \\
\hline B1 & \multirow{3}{*}{ Geocell-reinforced slope } & \multirow{3}{*}{ Planting soil, geocell reinforcement } & 50 \\
\hline B2 & & & 75 \\
\hline B3 & & & 100 \\
\hline $\mathrm{C} 1$ & \multirow{3}{*}{ Composite reinforced slope } & \multirow{3}{*}{ Geocell and wheat straw reinforcement } & 50 \\
\hline $\mathrm{C} 2$ & & & 75 \\
\hline $\mathrm{C} 3$ & & & 100 \\
\hline
\end{tabular}

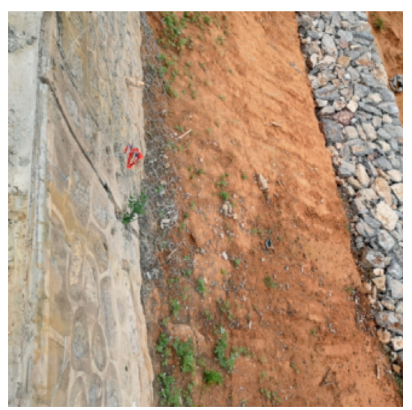

(a)

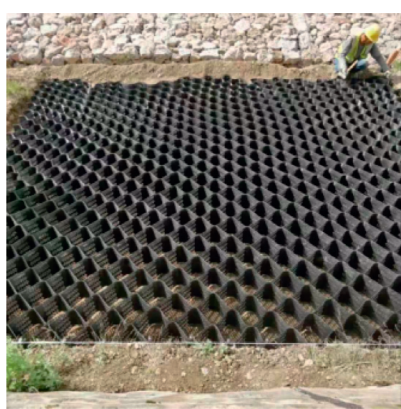

(b)

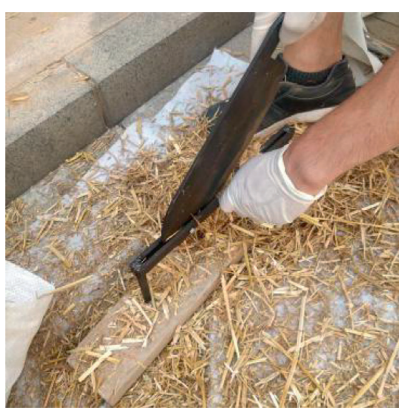

(c)

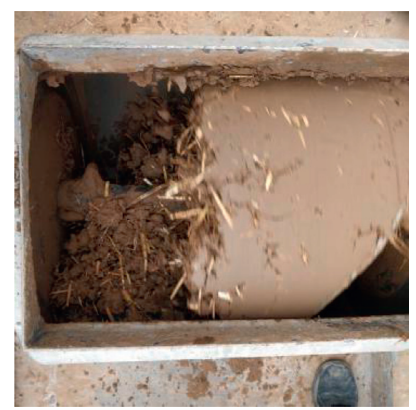

(d)

Figure 1: Modelling material preparation: (a) planting soil in the field; (b) geocell structures; (c) wheat straw cutting; (d) mixture of straw with the planting soil.

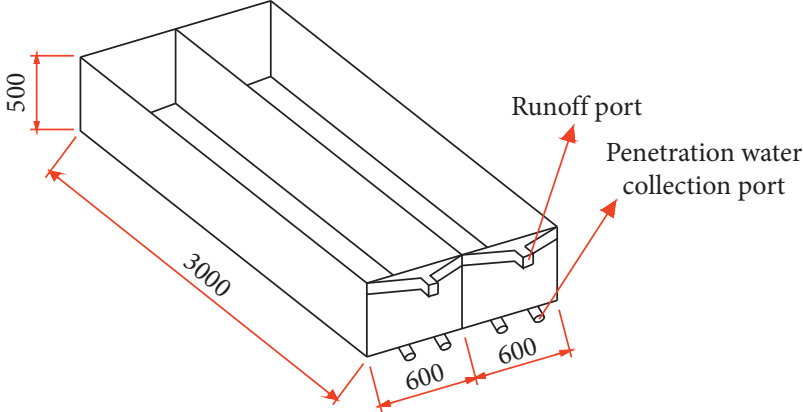

(a)

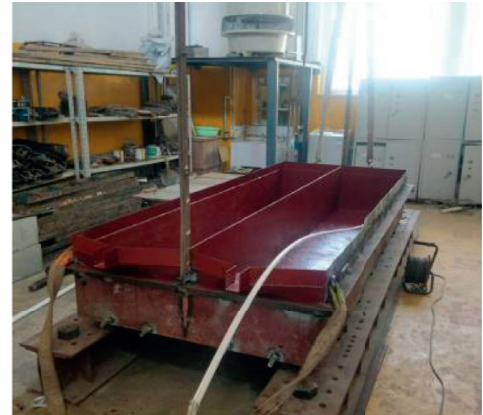

(b)

FIGURE 2: Modelling rig for simulating slope soil erosion treatment: (a) schematic; (b) forged rig.

by a camera, and the rest three parameters are recorded by the measuring system.

3.3. Soil Erosion Measurement. The finished model after construction was cured for at least $24 \mathrm{~h}$ before the artificial rainfall to make sure that the water content of the soil keeps the same at different depth. After the rainfall starts, the rain water was collected at the ports on the front end of the rig every 5 minutes, so that the mass $\left(\mathrm{m}_{\text {runoffi }}\right)$ and volume $\left(\mathrm{V}_{\text {runoffi }}\right)$ of the runoff (including rain water and soil) are obtained. The mass of the soil erosion is calculated from the following Equations:

$$
\begin{aligned}
m_{\text {soil }_{i}} & =\rho_{\text {soil }} V_{\text {soil }_{i}}=\rho_{\text {soil }} \frac{m_{\text {runoff }_{i}}-\rho_{\text {water }} V_{\text {runoff }_{i}}}{\rho_{\text {soil }}-\rho_{\text {water }}}, \\
m_{\text {soil }_{\text {accum }}} & =\sum_{1}^{i} m_{\text {soil }_{i}},
\end{aligned}
$$

where $m_{\text {runoffi }}$ is the mass of the collected runoff from the port (including rain water and soil) at each collection, $g$; 


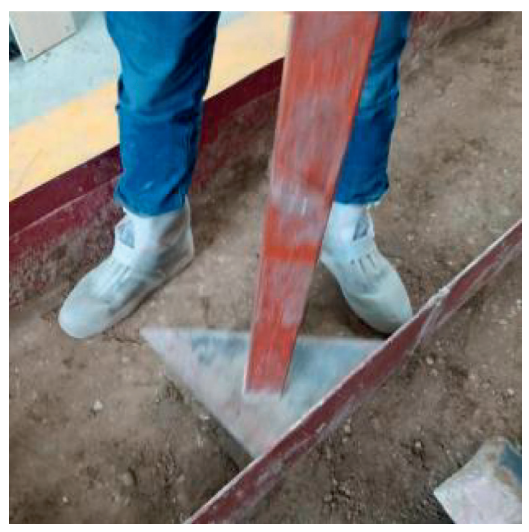

(a)

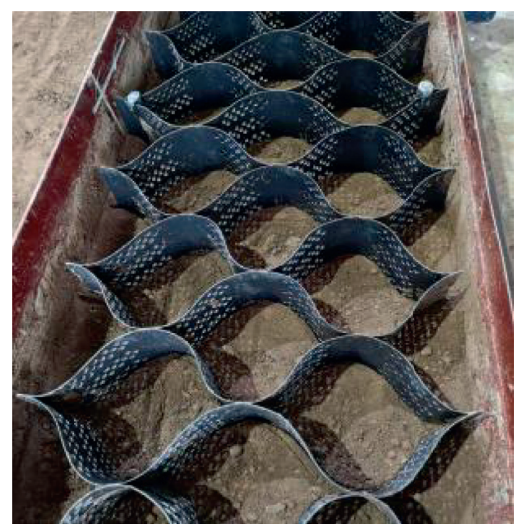

(b)

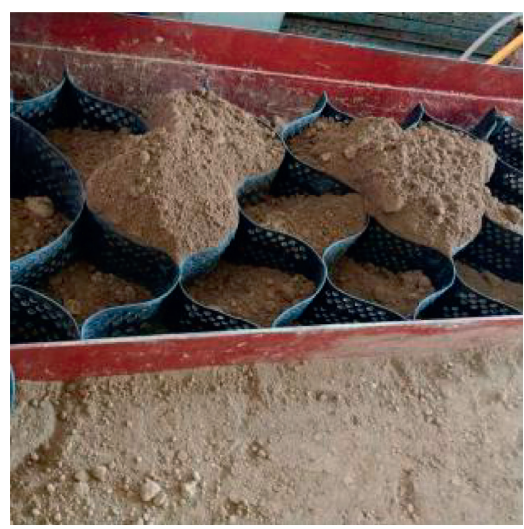

(c)

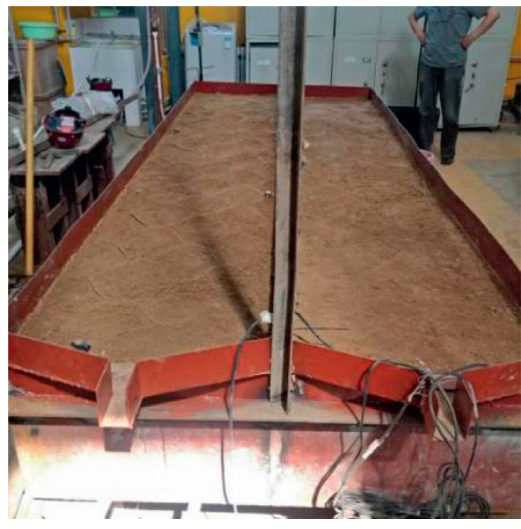

(d)

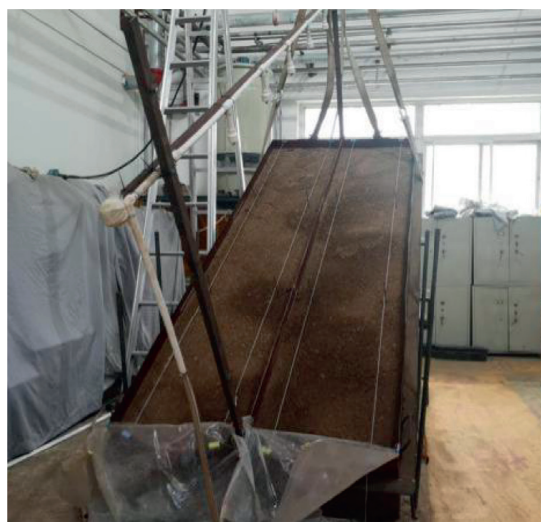

(e)

Figure 3: Model construction: (a) compaction of base soil; (b) placement of geocells; (c) fill of slope soil; (d) finished model; (e) finished model at a slope ratio of $1: 1.5$.

$V_{\text {runoffi }}$ is the volume of the collected runoff from the port (including rain water and soil) at each collection, $\mathrm{cm} \mathrm{[3];}$ $m_{\text {soili }}$ is the mass of the soil from the $i_{\text {th }}$ collected runoff in $g$; $V_{\text {soili }}$ is the volume of the soil from the $i_{\text {th }}$ collected runoff in $\mathrm{cm}[3] ; \rho_{\text {soil }}$ is the density of the slope soil before rainfall selected as $2.7 \mathrm{~g} / \mathrm{cm}^{3} ; \rho_{\text {water }}$ is the density of water, $1 \mathrm{~g} / \mathrm{cm}^{3}$; $m_{\text {soilaccum }}$ is the accumulated mass of the soil from total 6 collected runoffs, $g$; and $i$ is the number of runoff collected from the port $i=1,2, \ldots \ldots, 6$.

3.4. Slope Displacement Measurement. The displacement of the slope is measured using the measuring ruler fixed on the modelling rig. Since the rods move with the displacement of the slope, a fixed position should be selected for reference to calibrate the measurement. Therefore, a number of positioning marking rods were buried into the soil. Figure 5(a) gives a schematic of the positions of the rods. The rods on spots $t_{1}-t_{4}$ are placed at $1000 \mathrm{~mm}$ to the rear plate of the rig, while $b_{1}-b_{4}$ at $1000 \mathrm{~mm}$ to the front plate. A marking string parallel to the rig length direction is used to facilitate the displacement measurement (Figure 5(b)). The movement of the rods measured by the fixed ruler during rainfall represents the slope displacement at the top and bottom positions. For instance, the slope displacement at the top section of the slope is selected as the average value measured at spots $t_{1}$ and $t_{2}$ (Figure 5(c)). The slope displacement obtained from the poles was read at every 10 minutes during the rainfall and at every 15 minutes after the rainfall for 30 minutes.

3.5. Water Content Measurement. The soil moisture content of the slope was tested using the water content testing device (type SDI-12) buried into the slope soil during the construction. Two of the devices were used for each slope model. Both were embedded at the central position of the slope, with one buried at $10 \mathrm{~cm}$ below the surface $\left(\mathrm{N}_{1}\right.$ and $\mathrm{S}_{1}$ in Figure 5(a)) and the other at $20 \mathrm{~cm}$ depth $\left(\mathrm{N}_{2}\right.$ and $\left.\mathrm{S}_{2}\right)$. The water content data were collected every one minute, from the beginning of the rainfall to 30-35 minutes after the experiment ceases. Therefore, the variation of the water content of the slope at the shallow and deep depth of the soil was obtained during and after the rainfall.

\section{Results and Analysis}

4.1. Slope Failure Development. The progressive development of the slope failure is shown in Figure 6. Note that the unsupported slope was constructed in the right side of the 


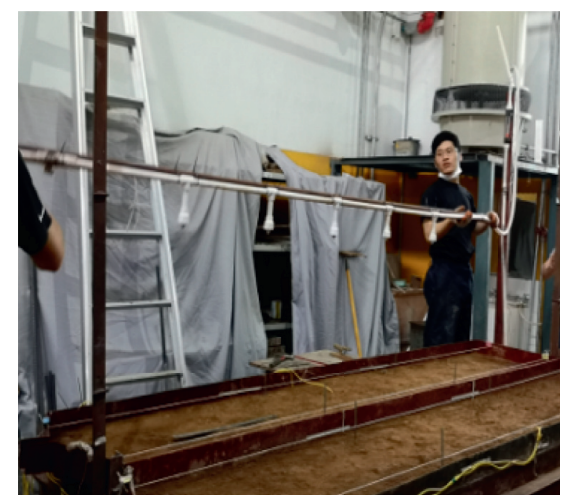

FIGURE 4: Rainfall simulation sprayers installed above the model.

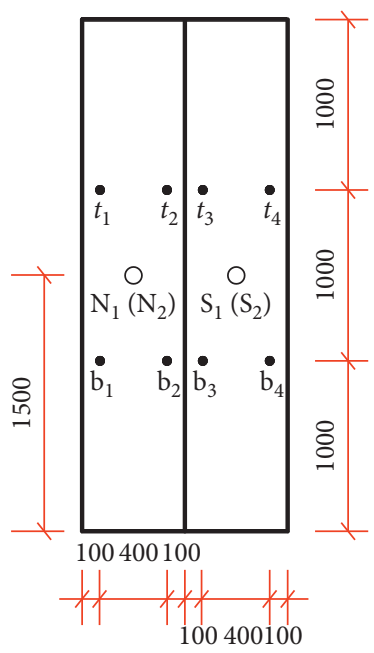

(a)

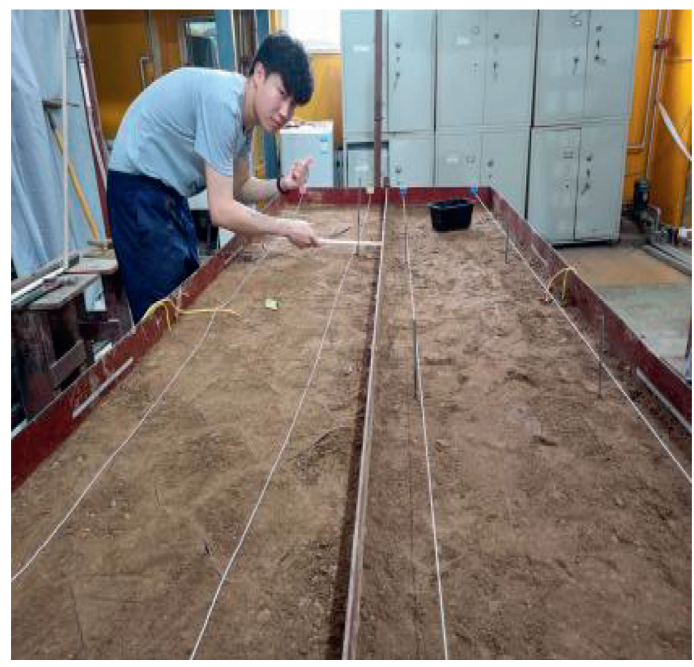

(b)

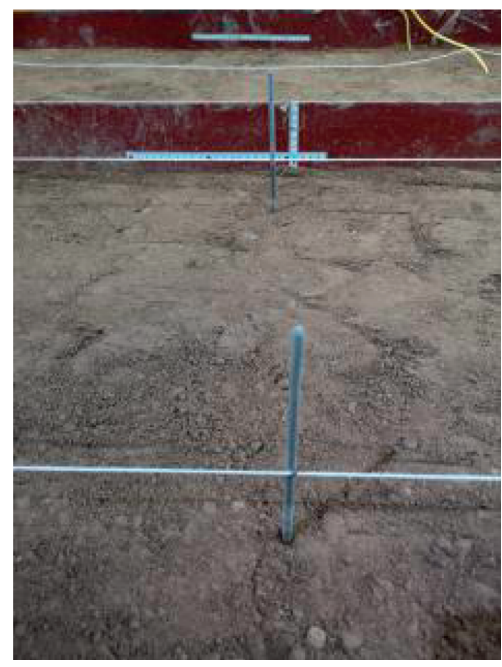

(c)

Figure 5: Placement of measurements: (a) schematic to show positions of marking rods and water content testing devices; (b) marking string to facilitate the slope displacement measurement; (c) positioning rods.

modelling rig, and the left side contains the geocell-reinforced one. The flow of rain water downward the slope surface is observed after 2 minutes of rainfall for both slopes. The runoff starts to scour away the surface soil, and the failure at the toe of unsupported slope is shown after 5 minutes of rainfall (Figure 6(a)). The soil degradation particularly at the lower side of the unsupported slope continues with the rainfall, but the reinforced slope shows good integrity (Figure 6(b)). The area of soil erosion increases on the unsupported slope as the rainfall continues for another 5-8 minutes, and the soil deterioration at toe is also observed on the reinforced slope (Figures 6(c) and 6(d)). The reappeared geocell indicates the shrink of the inner soil, which is held in position by the geocell rather than flowing with the running rain water. The rainfall further engraves the surface soil for both slopes and takes away a great amount of eroded soil (Figures 6(e) and 6(f)). A horizontal crack with a width of $0.8 \mathrm{~cm}$ is shown on the top of the unsupported slope after 20 minutes of rainfall (Figure 6(e)), and grows to about $3 \mathrm{~cm}$ when the rainfall continues for 26 minutes (Figure 6(f)). This is mainly due to the differential displacement of the upper layer of soil between the top and bottom of the unsupported slope, while the cracks are not seen on the reinforced model.

After 30 minutes of rainfall at the intensity of $100 \mathrm{~mm} / \mathrm{h}$, the final characteristics of the three slopes are shown in Figure 7, including the unsupported slope in Figure 7(a), the geocell-reinforced slope in Figure 7(b), and the geocell and wheat straw composite reinforced slope in Figure 7(c). Apparently, the unsupported slope shows the most damage to the surface soil. The previous observed horizontal fractures with a width of $1 \mathrm{~cm}$ were scoured by the rainfall and are now filled with the running mud from the top. The slope with geocell reinforcement is relatively better off, but the upper part of the buried geocell is reappeared under the rainfall, especially for those installed at the top side of the 


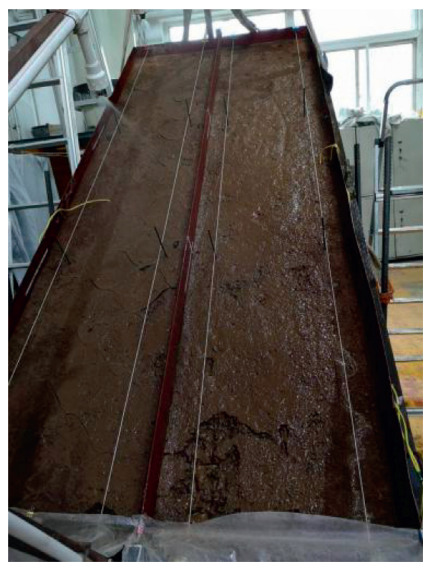

(a)

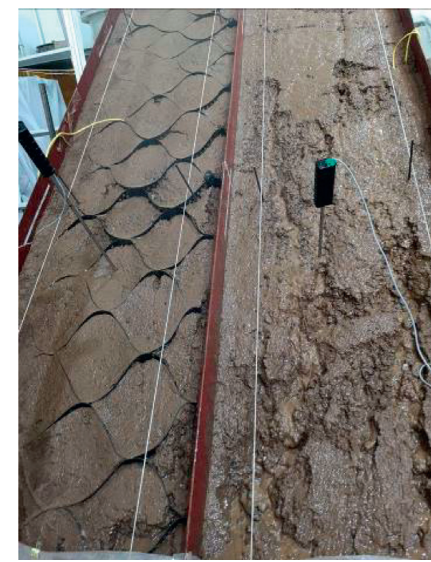

(d)

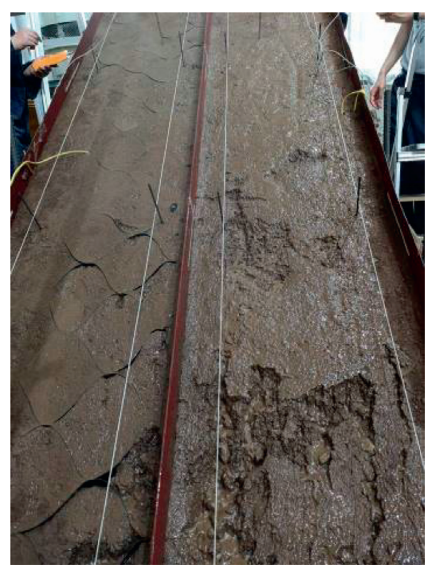

(b)

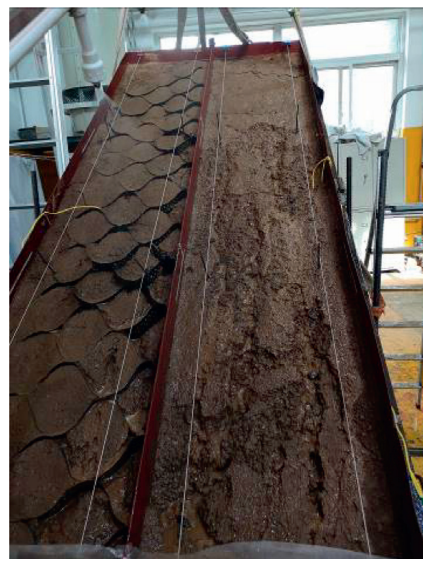

(e)

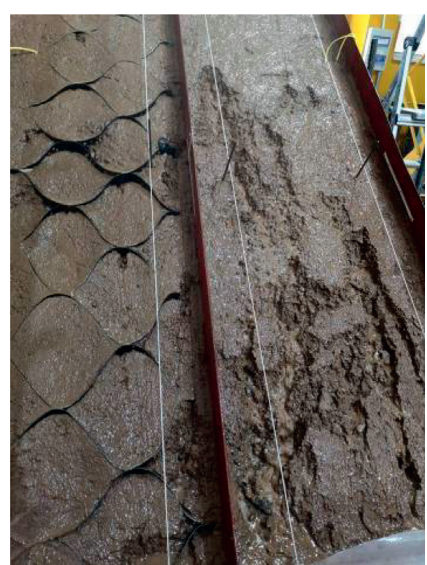

(c)

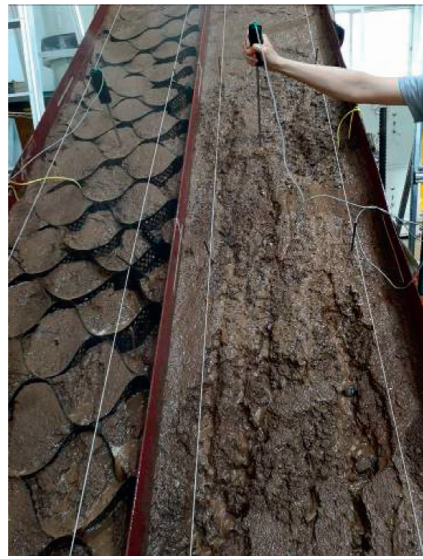

(f)

FIGURE 6: Development of slope erosion during rainfall. Left: geocell-supported slope; right: unsupported slope. (a) 5 min. (b) 7 min. (c) $12 \mathrm{~min}$. (d) $15 \mathrm{~min}$. (e) $20 \mathrm{~min}$. (f) $26 \mathrm{~min}$.

slope. The deep gullies indicate the loss of soil. By contrast, the composite reinforced slope shows the least damaged surface after the rainfall. This is because the wheat straw increases the internal friction angle and cohesion of the planting soil, which limits the soil erosion from the raindrops and surface runoff. The geocell also prevents the development of horizontal fractures, which slows down the erosion of the runoff.

4.2. Amount of Soil Erosion. Figure 8 gives the amount of soil erosion from the three slopes under different rainfall intensities. The lost soil was collected and recorded by a gauge every 5 minutes during the rainfall. The soil erosion increases with the rainfall and reaches the largest amount after 30 minutes at the cease of rainfall. Under the three rainfall intensities, the unsupported slope shows the largest amount of soil erosion, followed by the geocell-supported and the composited slopes in the descending order. For instance, at the rainfall intensity of $50 \mathrm{~mm} / \mathrm{h}$, the largest amount of soil erosion at the cease of rainfall is $543.1 \mathrm{~g}$ for the unsupported slope, which is significantly reduced to $298.5 \mathrm{~g}$ for the geocell-reinforced slope (a 45\% reduction) and only $38.1 \mathrm{~g}$ for the composite reinforced one (a 93\% reduction). It is therefore not unreasonable to conclude that the loss of eroded soil under rainfall is largely controlled by the erosion control treatment, especially by the geocell and straw composite reinforcement.

A dramatic rise in the soil erosion is observed as the rainfall intensity increases. At the rainfall intensity of $75 \mathrm{~mm} / \mathrm{h}$, the lost soil from the unsupported slope increases to 9096.9 g. A $72 \%$ of reduction is found in the amount of soil erosion for the geocell treatment slope $(2509.0 \mathrm{~g})$, and an $84 \%$ of reduction for the composite reinforcement $(1430.8 \mathrm{~g})$, implying that both the erosion control treatments work well under a moderate rainfall. At the rainfall intensity of $100 \mathrm{~mm} / \mathrm{h}$, however, the amount of soil erosion for the unsupported and geocell-reinforced slopes is both raised to an extremely high level at $22452.7 \mathrm{~g}$ and $20928.3 \mathrm{~g}$, respectively. The composite reinforced slope sees an $82 \%$ of reduction as compared to the unsupported model, indicating that the geocell and wheat straw composite treatment is more effective in protecting the slope and preventing the soil erosion especially under a heavy rainfall.

It is clear that the composite reinforced slope shows the best stability in terms of soil erosion after the rainfall. This is because the reappeared geocell after the washout of the 


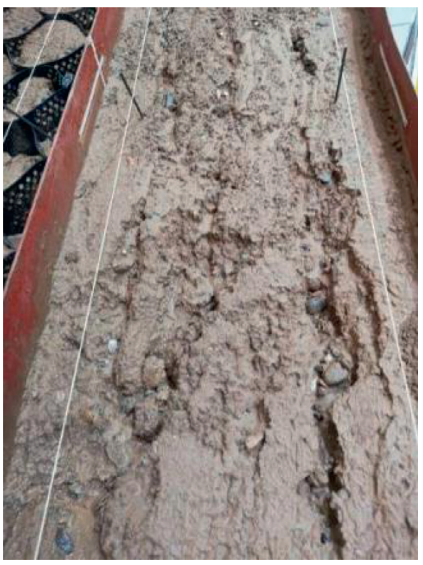

(a)

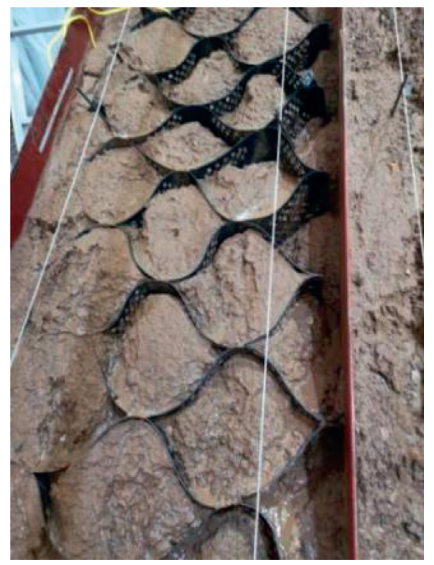

(b)

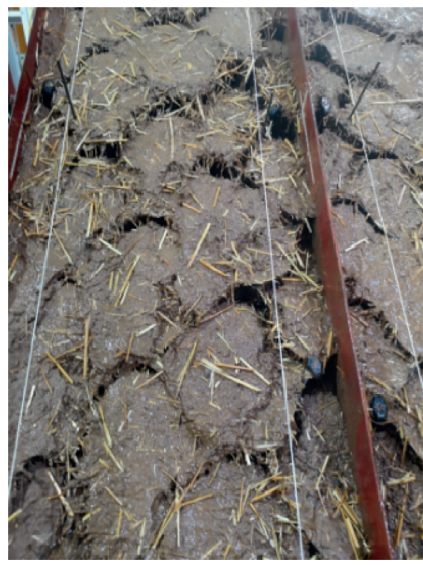

(c)

Figure 7: Comparison of slope erosion after rainfall: (a) unsupported slope; (b) geocell-reinforced slope; (c) geocell- and wheat strawreinforced slope.

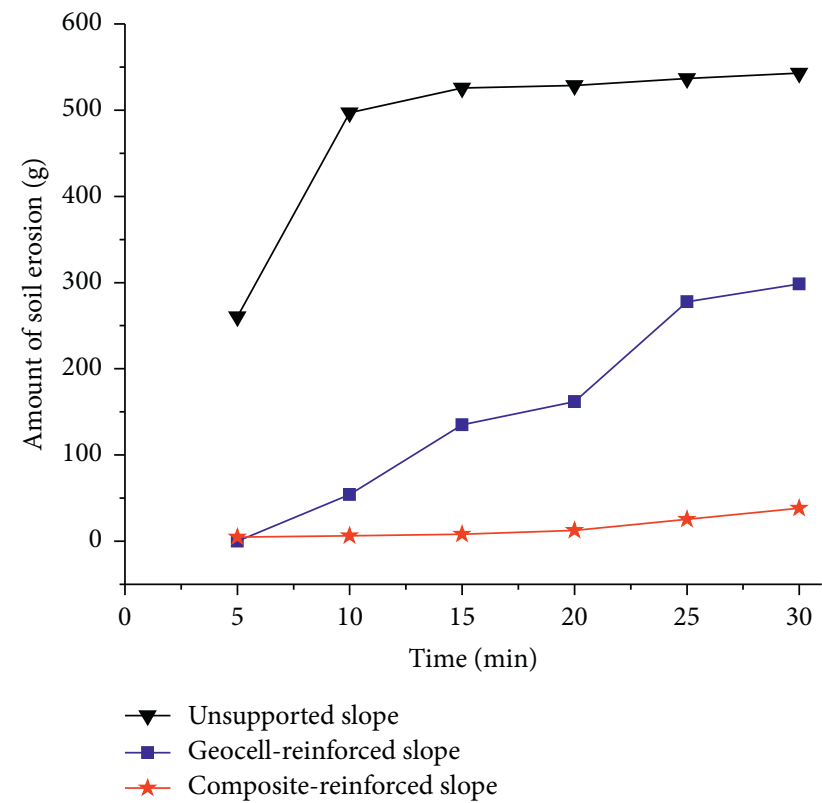

(a)

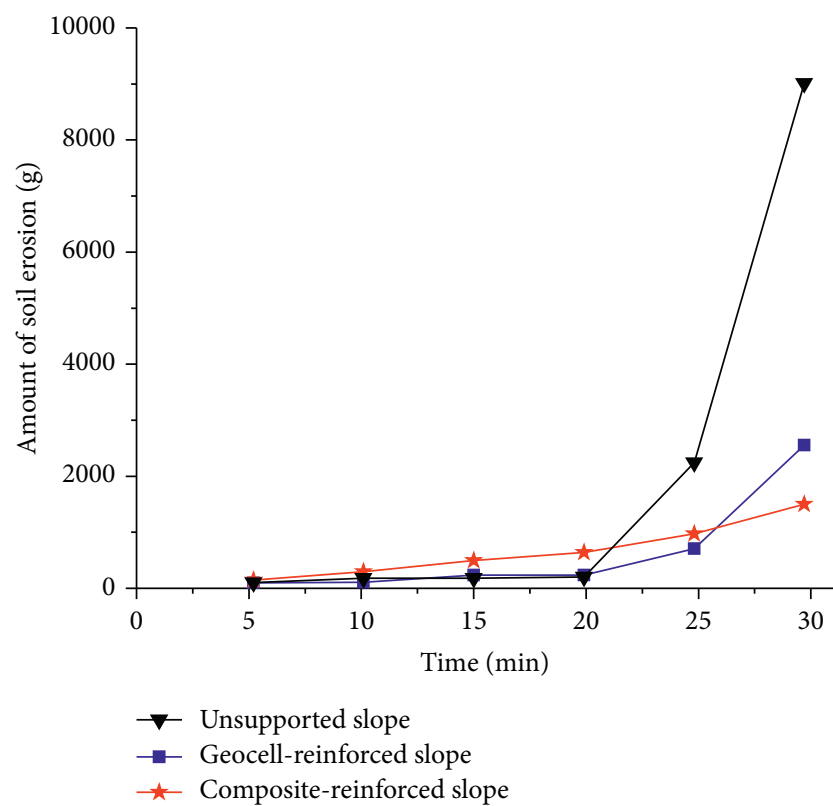

(b)

Figure 8: Continued. 


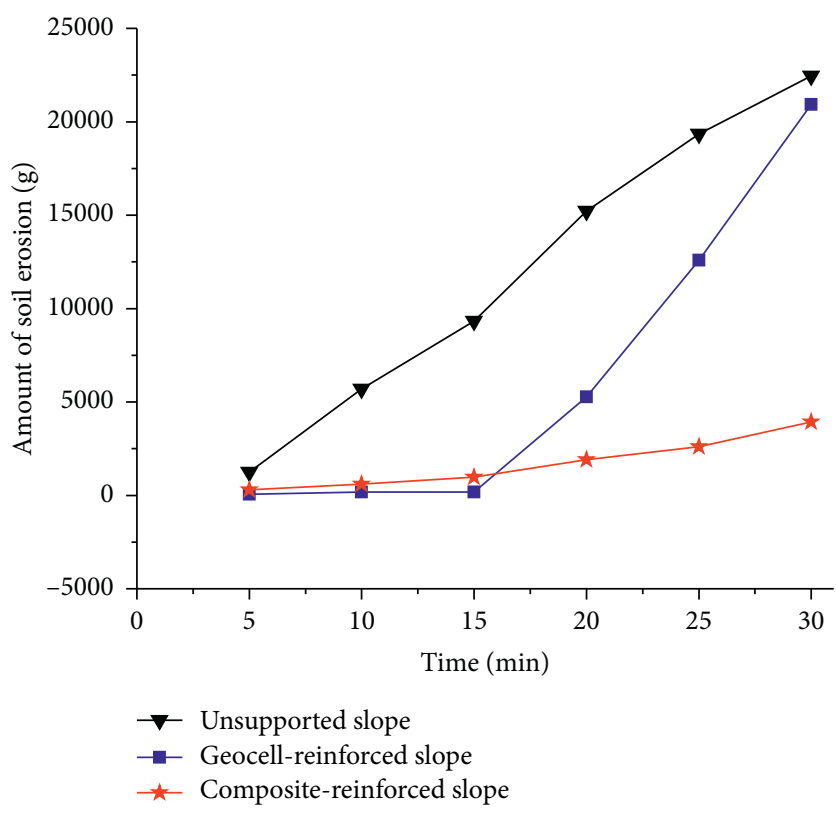

(c)

FIGURE 8: Amount of erosion soil during rainfall: (a) rainfall intensity: $50 \mathrm{~mm} / \mathrm{h}$; (b) rainfall intensity: $75 \mathrm{~mm} / \mathrm{h}$; (c) rainfall intensity: $100 \mathrm{~mm} / \mathrm{h}$.

surface soil hinders the flow of the rainwater and reduces the negative impact of the rainfall. The geocell also protects the inner soil and prevents the forming of a large-sized gully. The wheat straw in the top layer may improve the integrity of the slope by increasing the shear strength. The penetration is also reduced due to the smaller porosity for the strawreinforced soil. On the other hand, the scouring of the rain water down the unsupported slope results in a number of horizontal fractures and gullies with filled water. The penetration of rain water into soil also increases the pore pressure and reduces the shear strength of the soil. Therefore, the unsupported slope is more deteriorated with far more soil erosion.

4.3. Slope Displacement. The slope movement for different models at different rainfall intensities is given in Figure 9. The unsupported slope shows the largest displacement, followed by the geocell-reinforced slope and the geocell and straw composite reinforced. The slope displacement increases dramatically during the 30 minutes of rainfall. This increase slows down after the cease of rainfall. The slope stabilizes and shows unnoticeable slippage at 15 minutes after the rainfall stops. It seems that the bottom of the slope is more likely to slide, since the lower part of the slope generally displaces more as compared to the upper part. This might be due to the high water content at the bottom section of the slope: the soil is saturated first at the bottom; the range of saturated soil then develops upward with the rainfall, with reduced shear strength.

On the other hand, the slope displacement increases with the increase of rainfall intensity from $50 \mathrm{~mm} / \mathrm{h}$ to $100 \mathrm{~mm} / \mathrm{h}$.
Under the rainfall intensity of $100 \mathrm{~mm} / \mathrm{h}$, the slope displacements stay at a relative high level at more than $12 \mathrm{~mm}$ and $7.3 \mathrm{~mm}$ for the unsupported and geocell-reinforced slopes, respectively, while the difference in displacement between the top and bottom is unnoticeable. The composite reinforced slopes show a larger difference between the top and bottom sides, indicating that the reinforcement has a better control to the top side.

The bottom slope is more saturated and presents larger displacement, but the difference in displacement between the top and bottom of the slope may eventually trigger the landslide. This is why horizontal cracks were observed on top position of the slope. However, the erosion of the slope may occur from the bottom to top if no reinforcement is provided. The reinforcement works well to prevent the slope movement and increase the stability. The reinforcement from the geocell and the straw protects the slope soil from erosion; the slope surface is therefore more intact with less displacement.

4.4. Water Content Analysis. The change of water content in the slope soil during rainfall is given in Figure 10 for different models. At the beginning of rainfall, the water content is about $15 \%$ for different slopes, and it stays at this level for a few minutes of rainfall before starting to increase. The water content then climbs rapidly until it maximizes at around $40 \%$. Note that the sequence of the sudden increase of water content on the curve indicates the sequential order of water reaching the buried sensors in the soil. Generally, during the increasing stage, the sensors at $10 \mathrm{~cm}$ below the slope surface (see the solid dots) perceive the rainfall before those setting at $20 \mathrm{~cm}$ deep, i.e., the shallow soil shows larger water 


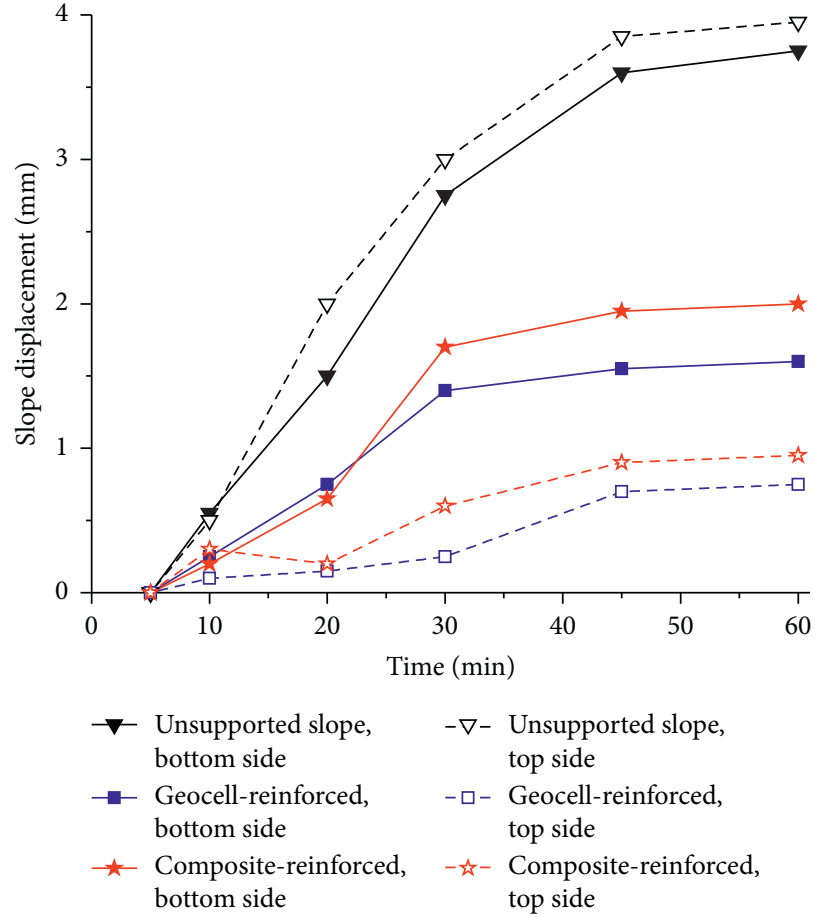

(a)

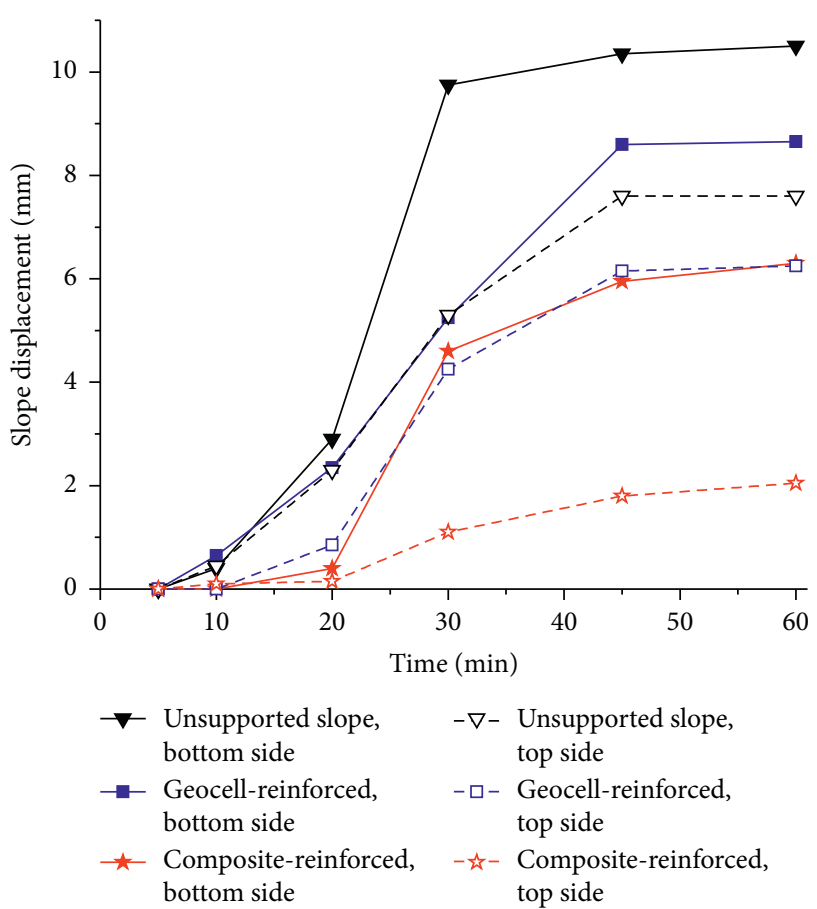

(b)

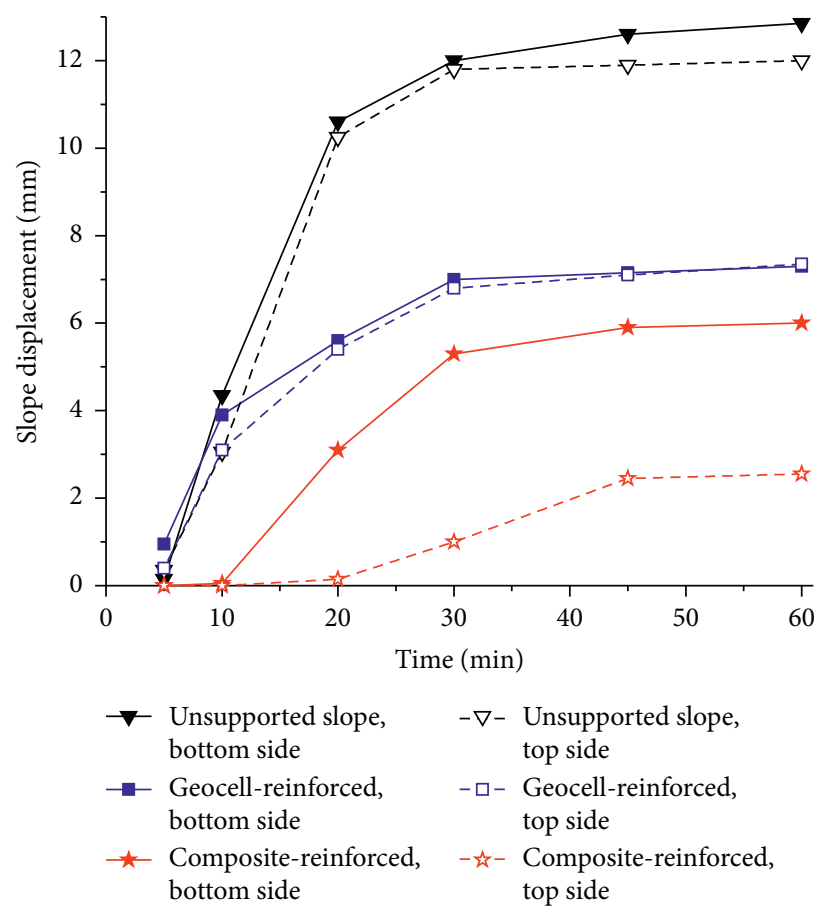

(c)

FIGURE 9: Slope displacement during rainfall: (a) rainfall intensity: $50 \mathrm{~mm} / \mathrm{h}$; (b) rainfall intensity: $75 \mathrm{~mm} / \mathrm{h}$; (c) rainfall intensity: $100 \mathrm{~mm} / \mathrm{h}$.

content than the deep soil. For the unsupported and geocellreinforced slopes, the increases of water moisture start almost at the same time, and the rates of water penetration represented by the slopes of curves are also similar. By comparison, the water content for the geocell- and strawreinforced slope starts to increase only after 13 and 25 minutes at the $10 \mathrm{~cm}$ at $20 \mathrm{~cm}$ depth, respectively, and reaches the maximum level 10-20 minutes later than the other two slopes. The rate of the increase of water content is also smaller than the other two slopes, indicating the geocell and straw reinforcement is more effective in slowing down the penetration of the rainfall. 


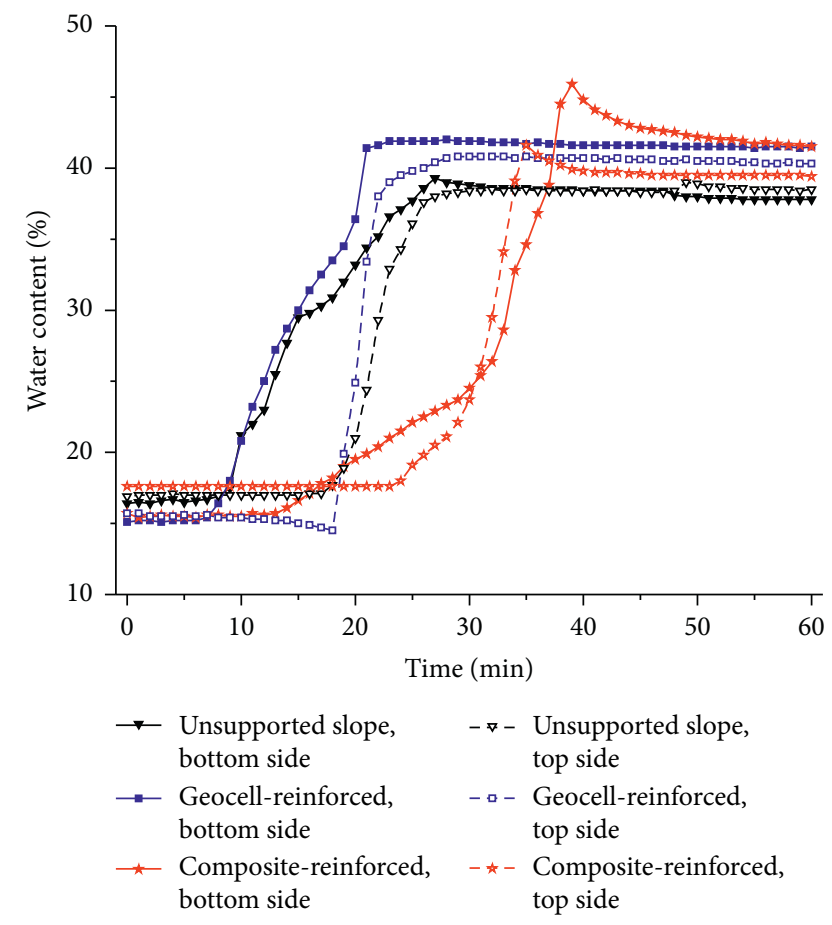

Figure 10: Variation of water content in the slope soil during rainfall.

\section{Summary and Conclusions}

Erosion control using planting vegetation for slope protection requires an adequate early stability of the planting soil. Otherwise, the collapse of the planting soil leads to the failure of the protective layer. This paper has proposed a composite soil treatment method using the geocell structures and the wheat straw reinforcement. The geocell above the slope provides a relatively stable environment for the growth of vegetation, and the wheat straw enhances the mechanical properties of the reinforced soil. The interaction of the composite reinforcement mitigates the soil erosion and improves the slope stability. A total of nine experiments were performed in the work to assess the failure process of the slope, soil erosion, slope displacement, and water content under different support strategies and different rainfall intensities. Important findings of this study are listed as follows:

(1) The erosion of the slope soil starts from the bottom of the soil and increases with the rainfall. Rills and gullies are formed as the rain water dislodges and carries soil particles off the lope. After the rainfall, a few horizontal cracks are observed on top of the slopes. This might be a result of the movement of the bottom soil pulling down the top soil. The unsupported slope shows the most damage of the soil, while the geocell and straw composite supported slope shows the best integrity.

(2) The soil erosion increases with the intensity of rainfall, but the slope reinforcement with geocell and wheat straw significantly reduces the rate and amount of the eroded soil. The unsupported slope shows that greatest amount of soil erosion under different rainfall intensities, but the geocell-reinforced slopes reduce the soil erosion to about $45-70 \%$, and the composite reinforced reduce $80-90 \%$.

(3) The slope displacement first increases with the rainfall and then slows down and stabilizes after the rainfall ceases. The composite reinforced slope has the least displacement, which sees a $30 \%$ and $60 \%$ reduction on average as compared to the geocellreinforced slope and the unsupported one. The displacement of the soil at bottom of the slope is more than that for the top soil. This discrepancy leads to the massive horizontal cracks observed at the top of the slope.

(4) The water content for different slopes increases from $15 \%$ at the beginning of rainfall and maximizes at $40 \%$ after the rainfall. The shallow depth soil has larger water content than the deep soil. The composite reinforcement slope shows the least rate of increase in water content, indicating that the geocell and wheat straw improve the slope stability by slowing down the penetration of water into soil.

\section{Data Availability}

The data used to support the findings of this study are included within the article.

\section{Conflicts of Interest}

The authors declare that there are no conflicts of interest.

\section{Acknowledgments}

The paper was supported by the Research Program for Key Technologies of Sponge City Construction and Management in Guyuan City (Grant no. SCHM-2018), Beijing Natural Science Foundation (Grant no. 2204080), and National Natural Science Foundation of China (Grant no. 52004010).

\section{References}

[1] X. Y. Sun, C. J. Mu, and X. H. Yang, "Application of the geocell in soil slopes at Yan-Lan line," Subgrade Engineering, vol. 4, pp. 55-57, 1999, in Chinese.

[2] G. W. Li, "Application of the geocell and planting vegetation on the road slope at swelling soil area," Journal of Highway and Transportation Research and Development, vol. 25, no. 4, pp. 46-48, 2008, in Chinese.

[3] K. Ren, X. S. Shen, H. X. Wang et al., "Application of the honeycomb shaped geocell in the hard slope at river side for ecological restoration-case study," Soil and Water Conservation in China, vol. 10, pp. 37-40, 2017, in Chinese.

[4] G. Y. Wang, Y. Han, and X. H. Wang, "Stability analysis of geocell flexible slope protection in rainfall," Rock and Soil Mechanics, vol. 33, no. 10, pp. 3020-3024, in Chinese. 
[5] X. H. Yang and W. S. Wang, "Application of geocell and vegetation in road slope protection at loess area," Highway, vol. 8, pp. 179-182, 2004, in Chinese.

[6] C. G. Yan, X. H. Yang, Y. L. Xie et al., "Experimental research on anti-eroding effect of geocells in loess embankment," Rock and Soil Mechanics, vol. 26, no. 8, pp. 1342-1348, in Chinese.

[7] A. Rosen, "The use of geocells for slope protection under special conditions," in Proceedings of the International Symposium on Design and Practice of Geosynthetic-Reinforced Soil Structures, Bologna, Italy, October 2013.

[8] T. Sato and K. Kojma, "Development of slope protection work using geocell and soil nailing," Japanese Railway Engineering, vol. 2018, no. 4, pp. 1-3, 2018.

[9] M. R. Arvin, A. Zakeri, and M. Bahmani Shoorijeh, "Using finite element strength reduction method for stability analysis of geocell-reinforced slopes," Geotechnical and Geological Engineering, vol. 37, no. 3, pp. 1453-1467, 2019.

[10] J. Wesseloo, A. T. Visser, and E. Rust, "The stress-strain behaviour of multiple cell geocell packs," Geotextiles and Geomembranes, vol. 27, no. 1, pp. 31-38, 2009.

[11] G. M. Latha, K. Rajagopal, and N. R. Krishnaswamy, "Experimental and theoretical investigations on geocell-supported embankments," International Journal of Geomechanics, vol. 6, no. 1, pp. 30-35, 2006.

[12] Y. R. Zheng, Z. Y. Chen, G. X. Wang et al., Management of Landslide, China Communications Publishing, Beijing, China, 2020.

[13] M. T. Löbmann, C. Geitner, C. Wellstein, and S. Zerbe, "The influence of herbaceous vegetation on slope stability-a review," Earth-Science Reviews, vol. 209, Article ID 103328, 2020.

[14] M. Bouhicha, F. Aouissi, and S. Kenai, "Performance of composite soil reinforced with barley straw," Cement and Concrete Composites, vol. 27, no. 5, pp. 617-621, 2005.

[15] T. Ashour, A. Bahnasawey, and W. Wu, "Compressive strength of fiber reinforced earth plasters for straw bale buildings," Australian Journal of Agricultural Engineering, vol. 1, no. 3, pp. 86-92, 2010.

[16] H. R. Zhang, G. Y. Wang, and L. C. Sha, "Experimental study on a rice-straw mud material for slope protection and anti erosion," Journal of Highway and Transportation Research and Development, vol. 34, no. 1, pp. 24-31, 2017, in Chinese.

[17] M. Donat, "Bioengineering Techniques for Streambank Restoration: A Review of Central European Practices," Watershed Restoration Project Report, vol. 2, pp. 4-9, 1995, in Chinese.

[18] L.-J. Su, B.-L. Hu, Q.-J. Xie, F.-W. Yu, and C.-L. Zhang, "Experimental and theoretical study of mechanical properties of root-soil interface for slope protection," Journal of Mountain Science, vol. 17, no. 11, pp. 2784-2795, 2020.

[19] J. B. Hao, X. M. Wei, J. Yao et al., "Strength characteristics and mesostructured of wheat straw reinforced soil," Journal of Tongji University (Natural Science), vol. 47, no. 6, pp. 764-768, 2019, in Chinese.

[20] Y. M. Shao and D. N. Shao, Updated Rainstorm Intensity Formula in China, China Architecture and Building Press, Beijing, China, 2014, in Chinese.

[21] Beijing General Municipal Engineering Design and Research Institute, City drainage, China Architecture and Building Press, Beijing, China, 2017, in Chinese.

[22] H. R. Zhang, G. Y. Wang, and L. C. Sha, "Experimental study on a rice-straw mud material for slope protection and antierosion," Journal of Highway and Transportation Research and Development, vol. 34, no. 1, pp. 24-31, 2017, in Chinese.
[23] H. B. Hu, L. C. Sha, and Y. J. Zhang, "Study on rain erosion test of the indoor slope protected by rice straw reinforced soil," Highway Engineering, vol. 43, no. 5, pp. 213-219, 2018, in Chinese.

[24] S. Y. Liu, Q. Z. Han, Z. G. Nie et al., "Study on characteristic and application of SB-YZCP artificial rainfall simulator," Journal of Soil and Water Conservation, vol. 4, no. 2, pp. 48-54, 1998, in Chinese.

[25] Y. Zhou, J. Wang, and S. W. Hu, "Designing and calibration of Kust 03-1 rainfall simulating system," Journal of Kunming University of Science and Technology (Natural Science), vol. 2, pp. 81-85, 2008, in Chinese. 